\title{
A Helicopter View of the Special Issue on Wave Energy Converters
}

\author{
Diego Vicinanza ${ }^{1, *}$ and Mariano Buccino ${ }^{2, *}$ \\ 1 Department of Civil Engineering, Design, Building and Environment, Second University of Napoli, \\ via Roma, 29, 81031 Aversa (Caserta), Italy \\ 2 Department of Civil, Architectural and Environmental Engineering, University of Napoli Federico II, \\ via Claudio, 21, 80125 Napoli, Italy \\ * Correspondence: diego.vicinanza@unina2.it (D.V.); buccino@unina.it (M.B.)
}

Academic Editor: Marc A. Rosen

Received: 14 February 2017; Accepted: 15 February 2017; Published: 17 February 2017

\begin{abstract}
This paper intends to provide the reader with an overview of the Special Issue on Wave Energy Converters. Through 16 contributions from authors of 10 different countries, a number of key topics have been tackled, including resource assessment, engineering design, and financial analysis. As a whole, the Special Issue forms an interesting and helpful compendium on the state of the art of wave energy extraction and exploitation.
\end{abstract}

Keywords: Wave Energy Converters; resource assessment; feasibility study; engineering design

Wave Energy (WE) has the potential to be a valuable contributor to the renewable energy mix, as it is abundant, inexhaustible, and relatively well predictable compared to other sources. Accordingly, it has aroused considerable interest over the last twenty years and more than 1000 Wave Energy Converters (WECs) have been patented worldwide.

Despite using a wide specter of variants, the working principles of WECs can be conveniently categorized into three groups, namely the Oscillating Water Column (OWC), Wave Activated Bodies (WAB), and OverTopping Devices (OTD). In the OWC technology, a cushion of air is trapped within a partly submerged chamber, where the water level rises and falls with the waves. The oscillating motion forces the air to pass through a turbine, which rotates in the same direction irrespective of the direction of flow. WABs exploit the relative motion of the different parts of the device; hydraulic systems are generally employed to compress oil, air, or water, which are then used to drive a generator. In the OTDs, a sloping plate leads the waves to overtop into a reservoir and the energy is extracted via a turbine that works with small head differences (below $3 \mathrm{~m}$ ) and large flow volumes.

In spite of the large body of work already carried out, WE is still far from being a real competitor of wind and photovoltaic energy, which are now commercially viable alternatives to fossil fuels. In view of this, the following research items deserve greater attention to speed up the development path:

(a) Assessment of the available and exploitable resources;

(b) New technical solutions to enhance the performance of the devices;

(c) Development of engineering tools for reliable technical and economical design;

(d) Analysis of the device impact on the marine environment;

(e) Development of criteria for optimization of the projects and feasibility analysis;

(f) Development of new technologies.

This Special Issue includes 16 papers from authors of 10 different countries, which provide the reader with food for thought on each of these topics. 
In Wave Energy Assessment and Performance Estimation of State of the Art Wave Energy Converters in Italian Hotspots [1], the offshore wave energy potential at the scale of the whole Mediterranean Sea was first evaluated. Then, the offshore data is propagated numerically for four Italian coastal areas. Interestingly, it was found that despite the available resources in Italy being up to 38 times less when compared to the most energetic European Union (EU) oceanic coasts, the power output expected from the WECs was only 9 times lower.

Wave Climate Resource Analysis Based on a Revised Gamma Spectrum for Wave Energy Conversion Technology [2] focused on the role of an accurate representation of the wave climate. In the paper, the authors revised and improved a methodology initially developed by the Electric Power Research Institute (EPRI) to estimate the naturally available and technically recoverable resource in a given deployment site. The approach employed a modified gamma spectrum, which was dependent on the calibration of two variables.

The problem of enhancing the efficiency of a WEC of the OWC type was addressed in Experimental Research on Primary and Secondary Conversion Efficiencies in an Oscillating Water Column-Type Wave Energy Converter [3]. Through physical model tests, the effects of the air chamber length and the guide vane setting angle were investigated. Furthermore, the performance of the Impulse Turbine as a secondary conversion device was studied both via steady air flow and 2D regular wave experiments.

In Experimental Test and Simulations on a Linear Generator-Based Prototype of a Wave Energy Conversion System Designed with a Reliability-Oriented Approach [4], the authors discussed the results of tests conducted on a permanent magnet linear electric generator for hydrogen production and storage in a WEC. The experiments allowed for the identification of the stator windowing typology and the ability to size the power electronics system.

Hydraulic Performance of an Innovative Breakwater for Overtopping Wave Energy Conversion [5] developed new design tools for the "OBREC", an OTD device totally embedded within a traditional rubble mound breakwater. Based on a series of random wave experiments conducted at Aalborg University (DK), new prediction formulae were calibrated for the calculation of the rate of energy reflected off the WEC and the amount of overtopping water. These predictive tools were then used to design the first OBREC prototype breakwater, in operation at the harbor of Napoli (Italy) since January 2016.

Experimental Validation of a Wave Energy Converter Array Hydrodynamics Tool [6] and The Use of CFD in the Analysis of Wave Loadings Acting on Seawave Slot-Cone Generators [7] were dedicated to the validation of previously developed predictors for the hydraulic and structural responses of converters.

The former analyzed the performance of a numerical design tool developed within the context of the linear potential flow theory, with the outcomes of a hydraulic model study carried out on an array of 5 point absorber WECs of the WAB type. As a peculiarity, in the experimental campaign the Power Take Off (PTO) system of each WEC was simulated to reduce the degree of uncertainty in the physical modeling.

The latter investigated the capability of Computational Fluid Dynamics to reproduce the structural response of an OTD named Seawave Slot-cone Generator (SSG), which includes a set of reservoirs placed on top of each other. The article presented an accurate comparison between the numerical test results and a set of prediction formulae developed based on a physical model study performed at the University of Napoli "Federico II" (Italy).

Experimental Measurement of Wave Field Variations around Wave Energy Converter Arrays [8] investigated the changes in the local wave field (and thus the coastal environment), induced by an array of five OWC-WECs. An experimental campaign was carried out in the Queen's University 3D coastal wave basin of the University of Belfast (UK) and both the scattered and radiated wave fields were accurately mapped through high resolution measurements of the surface elevation in the vicinity of the devices.

Two interesting feasibility studies were presented in Wave Energy Exploitation System Integrated in the Coastal Structure of a Mediterranean Port [9] and Economic Assessment of Overtopping BReakwater for 
Energy Conversion (OBREC): A Case Study in Western Australia [10]. Both papers addressed the problem of the economic convenience of integrating a WEC into an ordinary breakwater for harbor protection. The former considered the site of "Giardini Naxos", on the Northern Ionian coast of Sicily (Italy), and focused on a OWC to be integrated with a vertical breakwater. The paper also analyzed the structural feasibility of the project and discussed the results of physical model tests that were performed to assess the magnitude of wave loadings exerted on the structure.

The second article looked at the optimal configuration of an OBREC type WEC, in order to maximize the financial return. The Western coast of Australia, one of the most energetic environments worldwide, was selected as a reference site. Following the production tuning procedure and the concept of Reliability, Availability, Maintainability and Safety engineering (RAMS), it was demonstrated that very energetic patterns may lead to a "saturated" condition, where a considerable amount of resource is reflected off the WEC, thereby reducing the economic performance of the project.

Critical Factors Influencing Viability of Wave Energy Converters in Off-Grid Luxury Resorts and Small Utilities [11] examined the opportunity of employing wave energy plants in isolated power production systems, below $10 \mathrm{MW}$ capacity. These small markets can be considered as a test in view of future (long term) applications of WECs to large national grids. Three potential business cases were considered (Bora-Bora, Lanzarote, Maldives) and it was shown that all of them were significantly impacted by the available wave resource level, power demand, supply chain logistics, and the presence of alternative energy sources in the nearby area. These factors had by themselves the potential to kill the viability of a wave energy project.

Offshore Wind and Wave Energy assessment around Malù and Magoodhoo Island (Maldives) [12] considered just two atoll islands of the Maldives archipelago as a reference site to assess the performance of a multi-purpose project, including power generation from waves and wind, desalinization, and shore protection.

The problem of the optimum size of a multi-MW WEC array was tackled in Techno-Economic Related Metrics for a Wave Energy Converters Feasibility Assessment [13]. Using the Levelized Cost of Energy concept (LCOE), a detailed analysis was carried out in order to establish any dependence between the site location and optimal WEC size/rating. It was also proven that Energy Per Mass and Average Climate Capture Width per Characteristic Capital Expenditure (ACE) were both inversely correlated to LCOE through power relationships; this suggests that those quantities can be used as objective functions for optimization purposes when LCOE cannot be calculated properly.

The degree of innovation and financial appeal of a project were considered as components of a unique decisional path in Risk vs. Reward: A Methodology to Assess Investment in Marine Energy [14]. The article proposed a methodology where the development risk was assessed alongside LCOE, to ensure that unfeasible development strategies could be identified at an early stage and discarded, no matter how attractive the LCOE of the project may have seemed from a purely financial point of view. According to the early literature, the project development risk is assumed to be a function of the design difficulty (which reflects the risks presented by the technical complexity of the design) and the resource (which accounts for the risks presented by the physical resources required to complete the project).

A novel overtopping WEC was presented in Laboratory Tests in the Development of WaveCat [15]. The WaveCat consists of two symmetrical hulls joined to the stern via a hinge, allowing the relative angle between the hulls to be varied depending on the sea state. In addition, the freeboard of the device decreases along the inner edge towards the stern, allowing incoming waves to continue overtopping despite the reduction in height caused by the overpassing itself. Physical model tests at a 1:30 length-scale were performed in the Ocean Basin of the Coast Laboratory of the University of Plymouth (UK). The purposes of the experiments were to determine the performance of the Wave Cat under different sea-states, establish a starting point for optimization of the device, validate a predictive numerical model, and test the control system. 


\section{References}

1. Vannucchi, V.; Cappietti, L. Wave Energy Assessment and Performance Estimation of State of the Art Wave Energy Converters in Italian Hotspots. Sustainability 2016, 8, 1300. [CrossRef]

2. Pastor, J.; Liu, Y. Wave Climate Resource Analysis Based on a Revised Gamma Spectrum for Wave Energy Conversion Technology. Sustainability 2016, 8, 1321. [CrossRef]

3. Murakami, T.; Imai, Y.; Nagata, S.; Takao, M.; Setoguchi, T. Experimental Research on Primary and Secondary Conversion Efficiencies in an Oscillating Water Column-Type Wave Energy Converter. Sustainability 2016, 8, 756. [CrossRef]

4. Boscaino, V.; Cipriani, G.; Di Dio, V.; Franzitta, V.; Trapanense, M. Experimental Test and Simulations on a Linear Generator-Based Prototype of a Wave Energy Conversion System Designed with a Reliability-Oriented Approach. Sustainability 2017, 9, 98. [CrossRef]

5. Iuppa, C.; Contestabile, P.; Cavallaro, L.; Foti, E.; Vicinanza, D. Hydraulic Performance of an Innovative Breakwater for Overtopping Wave Energy Conversion. Sustainability 2016, 8, 1226. [CrossRef]

6. Mercadé Ruiz, P.; Ferri, F.; Kofoed, J.P. Experimental Validation of a Wave Energy Converter Array Hydrodynamics Tool. Sustainability 2017, 9, 115. [CrossRef]

7. Buccino, M.; Dentale, F.; Salerno, D.; Contestabile, P.; Calabrese, M. The Use of CFD in the Analysis of Wave Loadings Acting on Seawave Slot-Cone Generators. Sustainability 2016, 8, 1255. [CrossRef]

8. O’Boyle, L.; Elsäßer, B.; Whittaker, T. Experimental Measurement of Wave Field Variations around Wave Energy Converter Arrays. Sustainability 2017, 9, 70. [CrossRef]

9. Naty, S.; Viviano, A.; Foti, E. Wave Energy Exploitation System Integrated in the Coastal Structure of a Mediterranean Port. Sustainability 2016, 8, 1342. [CrossRef]

10. Contestabile, P.; Di Lauro, E.; Buccino, M.; Vicinanza, D. Economic Assessment of Overtopping BReakwater for Energy Conversion (OBREC): A Case Study in Western Australia. Sustainability 2017, 9, 51. [CrossRef]

11. Sandberg, A.B.; Klementsen, E.; Muller, G.; de Andres, A.; Maillet, J. Critical Factors Influencing Viability of Wave Energy Converters in Off-Grid Luxury Resorts and Small Utilities. Sustainability 2016, 8, 1274. [CrossRef]

12. Contestabile, P.; Di Lauro, E.; Galli, P.; Corselli, C.; Vicinanza, D. Offshore Wind and Wave Energy assessment around MalÙ and Magoodhoo Island (Maldives). Sustainability 2017, submitted.

13. De Andres, A.; Maillet, J.; Hals Todalshaug, J.; Möller, P.; Bould, D.; Jeffrey, H. Techno-Economic Related Metrics for a Wave Energy Converters Feasibility Assessment. Sustainability 2016, 8, 1109. [CrossRef]

14. Hutcheson, J.; de Andrés, A.; Jeffrey, H. Risk vs. Reward: A Methodology to Assess Investment in Marine Energy. Sustainability 2016, 8, 873. [CrossRef]

15. Allen, J.; Sampanis, K.; Wan, J.; Greaves, D.; Miles, J.; Iglesias, G. Laboratory Tests in the Development of WaveCat. Sustainability 2016, 8, 1339. [CrossRef] 